\title{
¿ES JURÍDICAMENTE VÁLIDO TENER DOS EMPLEOS SIMULTÁNEAMENTE EN MÉXICO?*
}

\author{
IS IT VALID TO HAVE SIMULTANEOUSLY TWO JOBS \\ IN MEXICO?
}

\author{
EST-CE LÉGALEMENT VALIDE D'AVOIR DEUX \\ EMPLOIS SIMULTANÉMENT AU MEXIQUE?
}

\section{Gloria Aurora DE LAS FuENTES LACAVEX**}

\begin{abstract}
RESUMEN: En México, la simultaneidad de empleos se regula por normas laborales diversas, en función de si el servicio se presta a un patrón de la iniciativa privada o a organismos descentralizados en los tres niveles de gobierno o si se presta a la administración pública centralizada, federal, estatal o municipal.
\end{abstract}

Palabras clave: empleos, simultaneidad, México.

ABSTRACT: In Mexico, job simultaneity is regulated by different labor regulations, depending if the service is rendered to a private boss or to a government decentralized organization in the three different branches of the government or if it is rendered to a centralized public, federal, state, or to a municipal administration.

Keywords: jobs, simultaneity, Mexico.

* Recibido el 6 de mayo de 2019 y aceptado para su publicación el 6 de septiembre de 2019.

** Doctora en derecho, por la UABC, profesora en la Facultad de Ciencias Administrativas y Sociales, campus Ensenada. Académica de número de la Academia Mexicana de Derecho del Trabajo y de la Previsión Social.

IS Revista Latinoamericana de Derecho Social Núm. 30, enero-junio de 2020, pp. 37-63 
RÉSUMÉ: Au Mexique, la simultanéité de l'emploi est régie par différentes réglementations du travail, selon si le service est rendu à un chef privé ou à une organisation décentralisée du gouvernement dans les trois parties du gouvernement, ou s'il est rendu à un bureau public centralisé, fédéral, national ou régional ou si c'est à une administration municipale.

Mots-clés: emplois, simultanéité, Mexique.

SumArio: I. Introducción. II. Fundamento constitucional. III. Ley Federal del Trabajo. IV. Servicio de conformidad con el derecho del trabajo y servicio de conformidad con el derecho burocrático. V. Ley Federal de los Trabajadores al Servicio del Estado. VI. Dos empleos de conformidad con el derecho burocrático. VII. Entidades federativas. VIII. Conclusión. IX. Bibliografía.

\section{INTRODUCCIÓN}

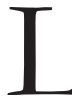

os trabajadores destinan su tiempo a la actividad económica que les sea miento de su familia y el propio. De esta forma no se convierten en una carga para sus parientes o para el gobierno. Esa actividad puede ser la prestación de un trabajo personal subordinado, tanto a un patrón de la iniciativa privada, así como a un patrón del sector público que puede ser federal, local o municipal.

Por lo general los trabajadores prestan ese servicio a un solo patrón, pero puede suceder que, por varios motivos, lo hagan a más de un patrón. Esta situación se regula jurídicamente de formas diversas, según se trate la naturaleza del patrón.

En esta colaboración se analizan diversas hipótesis de simultaneidad de empleos, reguladas por el derecho del trabajo y el derecho burocrático en México.

\section{FUNDAMENTO CONSTITUCIONAL}

En México, el artículo 5o. de la Constitución Política de los Estados Unidos Mexicanos (CPEUM) ${ }^{1}$ establece en el primer párrafo que a ninguna persona

\footnotetext{
1 Diario Oficial de la Federación (DOF), 5 de febrero de 1917.
} 
se puede impedir que se dedique a profesión, industria, comercio o trabajo que le acomode, siendo lícitos. Esta libertad sólo puede vedarse por determinación judicial, cuando se ataquen los derechos de tercero, o por resolución gubernativa, dictada en los términos que marque la ley, cuando se ofendan los derechos de la sociedad. Nadie puede ser privado del producto de su trabajo, sino por resolución judicial.

La prestación de un trabajo personal subordinado se regula por el artículo 123 constitucional, apartado A y apartado B y sus leyes reglamentarias. El apartado A regula la prestación de un trabajo personal subordinado a centros de trabajo considerados como de la iniciativa privada, así como a los organismos descentralizados de la administración pública. La ley reglamentaria es la Ley Federal del Trabajo (LFT). ${ }^{2}$ Surge así el derecho del trabajo, que se define como "el conjunto diferenciado de normas que regulan el mercado de empleo, la elación individual de trabajo asalariado y la organización y actividad de las representaciones profesionales de trabajadores y empresarios". 3

El apartado B regula la prestación de un trabajo personal subordinado a la administración pública federal centralizada. La ley reglamentaria es la Ley Federal de los Trabajadores al Servicio del Estado (LFTSE). ${ }^{4}$ Surge así el derecho burocrático, que se define como “...el sistema racional de normas jurídicas que tiene por objeto regir la relación de trabajo que surge entre el Patrón-Estado y sus servidores públicos". ${ }^{5}$ En México se excluye del derecho laboral burocrático a los organismos descentralizados, que se regulan por el apartado A del artículo 123 constitucional y, por ende, por la LFT, por resolución del Pleno de la Suprema Corte de Justicia de la Nación (SCJN), por jurisprudencia definida, en la que resolvió que la inclusión de los organismos descentralizados en el artículo 1o. de la LFTSE, es inconstitucional. ${ }^{6}$

El elemento distintivo, en relación con otros vínculos jurídicos, tanto en el derecho del trabajo como en el derecho burocrático, es la relación de subordinación, es decir, la prestación de un servicio a cambio de un salario.

2 DOF, 1o. de abril de 1970.

3 Martín Valverde, Antonio et al., Derecho del Trabajo, Madrid, Tecnos, 2003, p. 50.

4 DOF, 28 de diciembre de 1963.

5 Bolaños Linares, Rigel, Derecho laboral burocrático. Lecciones para el patrón-Estado, los trabajadores de base y de confianza a su servicio y, sus prestadores de servicios personales y profesionales, México, Porrúa, 2010, p. 1.

6 Tesis P. /J. 1/96, Semanario Judicial de la Federación y su Gaceta, Novena Época, t. III, febrero de 1996, p. 52. 


\section{LEY FEDERAL DEL TRABAjO}

Por disposición del artículo 58 de la LFT, jornada de trabajo es el tiempo durante el cual el trabajador está a disposición del patrón para prestar su trabajo. Por lo anterior, esta norma debe interpretarse como que el trabajador dispone libremente del tiempo restante del día.

El numeral 69 de la LFT establece que, por cada seis días de trabajo, debe el trabajador disfrutar de un día de descanso, por lo menos, con goce de salario íntegro. De igual forma, el trabajador dispone libremente de ese tiempo.

Los días de descanso conmemorativo se regulan en el numeral $74^{7}$ del ordenamiento jurídico citado. En principio, los trabajadores no están obligados a prestar sus servicios en estos días, a menos que así lo hubiesen convenido con su patrón. Consecuentemente, el trabajador puede destinar ese tiempo a las actividades que así decida.

El trabajador que tenga más de un año de servicios tiene derecho a disfrutar de un periodo anual de vacaciones pagadas, que en ningún caso puede ser inferior a seis días laborables, y que aumenta en dos días laborables, hasta llegar a doce, por cada año subsecuente de servicios. Después del cuarto año, el periodo de vacaciones aumenta en dos días por cada cinco de servicios, según se establece en el artículo 76 de la LFT. Por lo anterior, esta disposición debe interpretarse en el sentido de que el trabajador puede disponer libremente de ese tiempo.

\section{Disposición del tiempo libre para prestar servicio a otro patrón}

Se concluye, consecuentemente que, en ejercicio de la libertad de trabajo, el trabajador puede prestar un servicio personal subordinado, durante el tiempo restante en relación con su jornada de trabajo, o el descanso semanal o bien los días de descanso conmemorativo o durante sus vacaciones, a otro patrón, con la única condición de que no exista traslape en el servicio, es decir, que se pretenda trabajar para dos patrones al mismo tiempo. Nacen así a la vida

7 Días de descanso obligatorio: 1o. de enero; primer lunes de febrero en conmemoración del 5 de febrero; tercer lunes de marzo en conmemoración del 21 de marzo; 1 o. de mayo; 16 de septiembre; tercer lunes de noviembre en conmemoración del 20 de noviembre; 1 o. de diciembre de cada seis años, cuando corresponda a la transmisión del Poder Ejecutivo Federal; 25 de diciembre, y los que determinen las leyes federales y locales electorales, en el caso de elecciones ordinarias, para efectuar la jornada electoral. 
jurídica más de una relación individual de trabajo, así como las obligaciones y derechos inherentes a la misma, para el trabajador y los diversos patrones.

En este caso, el trabajador debe ser inscrito por los diversos patrones en las instituciones de seguridad social que correspondan, Instituto Mexicano del Seguro Social (IMSS) e Instituto del Fondo Nacional de la Vivienda para los Trabajadores (Infonavit), y se deberán efectuar las aportaciones correspondientes. El trabajador debe elegir la Administradora de Fondos para el Retiro (Afore) de su preferencia. Lo anterior a efecto de que los diversos salarios que percibe de forma simultánea sean considerados para el cálculo de prestaciones en dinero o en especie a que se pudiera hacer acreedor, así como para efectos fiscales.

En esta hipótesis jurídica, para el caso de que el trabajador surtiera un riesgo de trabajo, bajo esta rama del seguro, es decir, un accidente de trabajo o una enfermedad general, por el cual se extendiera por el IMSS una incapacidad temporal o definitiva, con relación a la otra relación de trabajo, para evitar las inasistencias injustificadas, deberá ser incapacitado, temporal o definitivamente bajo la rama del seguro de enfermedad general.

\section{Servicio al mismo patrón en dos actividades diferentes}

También puede presentarse el caso de que un trabajador preste simultáneamente para un mismo patrón dos actividades diversas, en jornadas de trabajo diferentes, que puede ser en el mismo puesto de trabajo o en uno diferente.

En este caso, se han presentado dos interpretaciones: la primera que sostiene que no es posible que un trabajador labore dos jornadas para un mismo patrón y que el tiempo trabajado en la denominada segunda jornada, debe considerarse como jornada extraordinaria.

El Primer Tribunal Colegiado en Materia de Trabajo del Primer Circuito dictó, en este sentido, tesis aislada en la que sostiene que cuando el patrón se excepciona con el argumento de que el trabajador desempeñaba dos empleos distintos a su servicio, pretendiendo con ello liberarse de las reclamaciones relacionadas con la jornada vespertina, debe entenderse que la relación de trabajo fue una sola si el trabajador realizaba la actividad tanto de la jornada matutina como vespertina, bajo las órdenes del mismo patrón, por lo que obviamente no hubo dualidad de patrones, ni, por ende, dos relaciones de trabajo distintas, sino que se trató de una prestación de servicios realizada en dos turnos para una misma empresa. ${ }^{8}$

8 Tesis: Tribunales Colegiados de Circuito, Semanario Judicial de la Federación, Séptima Época, 1983, vol. 175-180, sexta parte, p. 119. 
El Primer Tribunal Colegiado del Décimo Séptimo Circuito sostuvo en una tesis aislada que en relación con la reclamación derivada de haberse laborado dos turnos seguidos, comúnmente denominados "dobletes", no impera el mismo principio probatorio que se sigue cuando se reclaman horas extras, pues si bien por lo que ve a éstas últimas, corresponde a la parte patronal acreditar la jornada de labores de conformidad con lo dispuesto por el artículo 784, fracción VIII, de la LFT, sin embargo, cuando se reclaman "dobletes" es al trabajador a quien corresponde demostrar, que en efecto laboró dos turnos continuos, toda vez que es un principio general del derecho, al que remite el artículo 17 de la citada ley laboral, que el que afirma está obligado a probar, y en la especie no se trata de un exceso en la jornada laboral, sino de una duplicación de la misma; por lo que si no se acredita esa circunstancia, es justa la determinación de la Junta de absolver a la parte demandada de efectuar su pago. ${ }^{9}$

La segunda sostiene que es válida esta figura de dos jornadas para un mismo patrón. La Cuarta Sala de la Suprema Corte de Justicia de la Nación, ha sostenido en una tesis aislada que en los casos en que un trabajador preste sus servicios a una empresa en dos jornadas ordinarias de trabajo, devengando por cada una de ellas el salario correspondiente, la indemnización por riesgo profesional debe determinarse con base en el salario que recibía por la jornada en que sufrió el riesgo y los aumentos correspondientes hasta que se determine su incapacidad, y no en la suma de ambos salarios. ${ }^{10}$

También en esta hipótesis jurídica, el trabajador que sea incapacitado por el IMSS, temporal o permanentemente, por riego de trabajo o enfermedad general, deberá ser incapacitado, para efectos de la segunda relación de trabajo, por enfermedad general, por la misma institución de seguridad social.

El Quinto Tribunal Colegiado en materia de Trabajo del Primer Circuito resolvió en una tesis aislada que de conformidad con el artículo 766, fracción II, de la Ley Federal del Trabajo, el juez a quo está en lo correcto al sostener que es procedente el incidente de acumulación, si el trabajador en dos procesos laborales por él instaurados contra la misma empresa, impetra su adscripción a los empleos diversos a que las causas se refieren. ${ }^{11}$

9 Tesis: XVII. 1o. 12 L. Tribunales Colegiados de Circuito, Semanario Judicial de la Federación y su Gaceta, Novena Época, t. XIII, febrero de 2001, pp. 1755, 2000.

10 Tesis: Cuarta Sala. Semanario Judicial de la Federación, Séptima Época, 1973, vol. 49, Quinta parte, p. 52.

11 Tesis: Tribunales Colegiados de Circuito, Semanario Judicial de la Federación, Octava Época, t. VIII, octubre de 1991, p. 198. 
El Tercer Tribunal Colegiado en materia de trabajo del Primer Circuito dictó tesis aislada en la que sostuvo que si en su escrito de demanda laboral el actor expresa que trabajaba para el mismo demandado en diferentes categorías, indicando que tenía en cada una de ellas salarios y horarios distintos, y señala que fue despedido injustificadamente de ambas categorías y ejercita las acciones que estima pertinentes, y el demandado reconoce solamente la relación de trabajo de uno de los empleos y niega que tuviera contrato de trabajo en relación con el otro encargo, corresponde al demandante acreditar la existencia del contrato y el hecho de no estar laborando en el puesto que fue negado, para que la Junta esté en condiciones de decidir en relación con el despido y las prestaciones reclamadas del mismo. ${ }^{12}$

\section{SERVICIO DE CONFORMIDAD CON EL DERECHO DEL TRABAJO Y SERVICIO DE CONFORMIDAD CON EL DERECHO BUROCRÁTICO}

También puede existir la hipótesis de que un trabajador preste servicios simultáneamente a un patrón particular, regulado por la LFT y a un patrón de la administración pública federal centralizada, regulado por la LFTSE.

En este caso, cada una de las relaciones individuales de trabajo se rige por la normatividad aplicable. La única exigencia es que no exista traslape de horarios. El trabajador se hace, en este caso, acreedor a las prestaciones laborales y de seguridad social correspondientes a cada una de las relaciones individuales de trabajo, de igual forma deben acatarse las disposiciones fiscales, derivadas del salario total que reciba.

Para el caso de que el trabajador fuese incapacitado, temporal o permanentemente, por riesgo de trabajo o por enfermedad general, en una de las dos relaciones de trabajo, deberá, para evitar inasistencias injustificadas, tramitar y obtener la incapacidad correspondiente por enfermedad general, para la segunda relación de trabajo.

\section{Ley Federal de los Trabajadores al SERvicio deL Estado}

La LFTSE no presenta un concepto de jornada de trabajo. De conformidad con el numeral 11 de este ordenamiento, que dispone que, en lo no

12 Tesis: Tribunales Colegiados de Circuito, Semanario Judicial de la Federación, Octava Época, t. V, Segunda Parte-1, enero-junio de 1990, p. 178. 
previsto por esta ley o disposiciones especiales, se aplican supletoriamente, y en su orden, la LFT, el Código Federal de Procedimientos Civiles (CFPC), las leyes del orden común, la costumbre, el uso, los principios generales de derecho y la equidad, debe entenderse que la jornada de trabajo es el tiempo que el trabajador está a disposición del patrón para prestar su servicio y, consecuentemente, el trabajador puede disponer libremente del resto del tiempo diario.

El numeral 27, determina que por cada seis días de trabajo disfruta el trabajador de un día de descanso, cuando menos, con goce de salario íntegro. De ello se deprende que el trabajador puede decidir a qué dedica ese día libre. ${ }^{13}$

El artículo 29 señala que son días de descanso obligatorio los que señala el calendario oficial y el que determinen las leyes federales y locales electorales, en el caso de elecciones ordinarias, para efectuar la jornada electoral. El trabajador resuelve qué hacer en los días de descanso conmemorativo.

Los trabajadores que tengan más de seis meses consecutivos de servicios disfrutan de dos periodos anuales de vacaciones, de diez días laborables cada uno, en las fechas que se señalen al efecto; pero en todo caso se dejan guardias para la tramitación de los asuntos urgentes, para los que se utilizan de preferencia los servicios de quienes no tuvieren derecho a vacaciones. Cuando un trabajador no pueda hacer uso de las vacaciones en los periodos señalados, por necesidades del servicio, disfruta de ellas durante los diez días siguientes a la fecha en que haya desaparecido la causa que impidiere el disfrute de ese descanso, pero en ningún caso los trabajadores que laboren en periodos de vacaciones tienen derecho a doble pago de sueldo. Lo anterior se regula en el artículo 30 de la LFTSE. De igual forma, el trabajador determina libremente a qué dedica el tiempo de vacaciones.

\section{DOS EMPLEOS DE CONFORMIDAD \\ CON EL DERECHO BUROCRÁTICO}

A diferencia de lo que se regula en el derecho del trabajo, en el derecho burocrático no basta, para la hipótesis de prestar servicio a dos patrones simultáneamente, con cargo al presupuesto federal, que no se traslapen las jornadas, sino que se cumpla con lo dispuesto en diversos ordenamientos jurídicos.

13 DOF, 28 de diciembre de 1972: Decreto del presidente Luis Echeverría, consigna beneficio para los burócratas federales que, por cada cinco días de trabajo, disfruten de dos días de descanso, preferentemente sábado y domingo, con goce de salario íntegro. 


\section{Constitución Politica de los Estados Unidos Mexicanos}

La CPEUM dispone en el numeral $62,{ }^{14}$ que los diputados y senadores propietarios, durante el periodo de su encargo, no pueden desempeñar ninguna otra comisión o empleo de la Federación o de las entidades federativas por los cuales se disfrute sueldo, sin licencia previa de la Cámara respectiva; pero entonces cesan en sus funciones representativas, mientras dure la nueva ocupación. La misma regla se observa con los diputados y senadores suplentes, cuando estuviesen en ejercicio.

\section{Ley Federal de Presupuesto y Responsabilidad Hacendaria}

La Ley Federal de Presupuesto y Responsabilidad Hacendaria (LFPRH) ${ }^{15}$ dispone en el artículo 1o., que se trata de un ordenamiento jurídico de orden público, y tiene por objeto reglamentar los artículos 74, fracción IV, 75, 126, 127 y 134 de la CPEUM, en materia de programación, presupuestación, aprobación, ejercicio, control y evaluación de los ingresos y egresos públicos federales. Los sujetos obligados a cumplir las disposiciones de esta ley deben observar que la administración de los recursos públicos federales se realice con base en criterios de legalidad, honestidad, eficiencia, eficacia, economía, racionalidad, austeridad, transparencia, control, rendición de cuentas y equidad de género. La auditoría fiscaliza el estricto cumplimiento de las disposiciones de esta ley por parte de los sujetos obligados, conforme a las atribuciones que le confieren la CPEUM y la Ley de Fiscalización Superior de la Federación (LFSF). ${ }^{16}$

El artículo 71 establece que, salvo lo previsto en las leyes, el Ejecutivo Federal, por conducto de la Función Pública, determina en forma expresa y general los casos en que procede aceptar la compatibilidad para el desempeño de dos o más empleos o comisiones con cargo a los presupuestos de las dependencias y entidades, sin perjuicio del estricto cumplimiento de las tareas, horarios y jornadas de trabajo que correspondan. En todo caso, los interesados pueden optar por el empleo o comisión que les convenga.

\footnotetext{
14 Reformado DOF, 29 de enero de 2016.

15 DOF, 30 de marzo de 2006.

16 DOF, 29 de diciembre de 2000.
} 


\section{El Reglamento de la Ley Federal de Presupuesto y Responsabilidad Hacendaria}

El Reglamento de la Ley Federal de Presupuesto y Responsabilidad Hacendaria ${ }^{17}$ regula en el numeral 138 que es compatible el desempeño de dos o más empleos, cargos o comisiones, o la prestación de servicios profesionales por honorarios en distintas dependencias y/o entidades, siempre y cuando el horario fijado para los mismos no interfiera entre sí, ni se genere conflicto de intereses en términos de las disposiciones aplicables. No es compatible el desempeño de dos o más plazas en una misma dependencia, entidad o unidad administrativa, excepto en aquellos casos relativos a plazas del sector educativo por horas o tiempo parcial u otras que se señalen en las disposiciones aplicables. La Función Pública debe expedir las disposiciones que deben observarse para aceptar el desempeño de dos o más empleos, cargos o comisiones, o la prestación de servicios profesionales por honorarios en las dependencias y entidades, y es la competente para determinar los casos en que proceda la compatibilidad y para aclarar los casos de duda que al respecto se presenten.

El Tercer Tribunal Colegiado en Materia de Trabajo del Primer Circuito, en una tesis aislada, resolvió que los artículos 32, 33 y 34 de la LFTSE establecen, respectivamente, que el sueldo asignado a los trabajadores, conforme a los tabuladores regionales, constituye el total que debe pagárseles a cambio de los servicios prestados, sin perjuicio de otras prestaciones ya establecidas; que éste debe ser uniforme para cada uno de los puestos del Catálogo General de Puestos del Gobierno Federal; que no puede ser disminuido durante la vigencia del presupuesto de egresos a que corresponda, y que por cada cinco años de servicios efectivos prestados hasta llegar a veinticinco, los trabajadores tienen derecho al pago de una prima como complemento del salario. Por tanto, si un trabajador labora en dos dependencias del gobierno federal cumpliendo el requisito de compatibilidad de honorarios y cada una de ellas le paga la prima quinquenal, este beneficio no puede ser suprimido por la entrada en vigor de la norma que regula el pago de la prima quinquenal, creada por la Secretaría de Hacienda y Crédito Público (SHCP), de 17 de marzo de 1998, ni por disposición administrativa en contrario, porque debido a que su naturaleza es de tipo administrativa no puede estar por encima de lo que establece la LFTSE. ${ }^{18}$

17 DOF, 28 de junio de 2006.

18 Tesis: I.13o. T. 45 L, Tribunales Colegiados de Circuito, Semanario Judicial de la Federación y su Gaceta, Novena Época, t. XVIII, octubre de 2003, p. 1120. 
El Séptimo Tribunal Colegiado en Materia Administrativa del Primer Circuito dictó tesis aislada, sosteniendo que de una interpretación sistemática de los artículos 17, 48, 62 y 64 de la Ley del Instituto de Seguridad y Servicios Sociales de los Trabajadores del Estado (LISSSTE), se desprende que para que un servidor público tenga derecho a que se tomen en consideración los sueldos percibidos en dos cargos al momento de fijar la pensión respectiva, es necesario que: a) en cada uno de los empleos se reúnan los requisitos de edad y antigüedad establecidos por la ley para el otorgamiento de una pensión, y b) ambos cargos se hayan desempeñado simultáneamente durante el año anterior al retiro del trabajador. ${ }^{19}$

El Noveno Tribunal Colegiado en materia Administrativa del Primer Circuito resolvió en una tesis aislada que cuando una pensión por jubilación se integra cotizando en dos plazas distintas, su incremento debe calcularse conforme a las reglas del artículo 57 de la Ley del Instituto de Seguridad y Servicios Sociales de los Trabajadores del Estado abrogada, vigentes al momento de la obtención de la pensión relativa a la plaza más antigua, si es lo que más beneficia al trabajador o a sus familiares..$^{20}$

\section{El Acuerdo por el que se emiten las disposiciones en las materias de Recursos Humanos y del Servicio Profesional de Carrera, así como el Manual Administrativo de Aplicación General en materia de Recursos Humanos y Organización y el Manual del Servicio Profesional de Carrera}

El Acuerdo por el que se emiten las disposiciones en las materias de Recursos Humanos y del Servicio Profesional de Carrera, así como el Manual Administrativo de Aplicación General en materia de Recursos Humanos y Organización y el Manual del Servicio Profesional de Carrera, ${ }^{21}$ contiene disposiciones que regulan la prestación del servicio profesional de carrera. Son de destacarse, entre otros, las siguientes: reclutamiento y selección; ingreso; capacitación; evaluación del desempeño, estímulos, reconocimientos e incentivos al desempeño destacado, separación; registro de servidores públicos del gobierno federal; compatibilidades; contratos de prestación de servicios profesionales por honorarios.

19 Tesis: I.7o. A.299.A, Tribunales Colegiados de Circuito, Semanario Judicial de la Federación y su Gaceta, Novena Época. t. XX, julio de 2004, p. 1761.

20 Tesis: I.9o.A.60 A (10a.), Tribunales Colegiados de Circuito, Gaceta del Semanario Judicial de la Federación, Décima Época, t. IV, libro 12, noviembre de 2014, p. 3012.

${ }^{21}$ DOF, 12 de julio de 2010. 
En el artículo tercero, capítulo VI, De las Compatibilidades, título tercero, De la Planeación de Recursos Humanos, establece que una persona puede desempeñar dos o más puestos, e incluso prestar servicios profesionales mediante contrato por honorarios con cargo al presupuesto de servicios personales, debiendo contar con el dictamen de compatibilidad entre el puesto que se propone desempeñar y el puesto o puestos que ya desempeña en una o varias instituciones, o entre el puesto que se propone desempeñar y las actividades $\mathrm{y} / \mathrm{o}$ funciones contenidas en uno o más contratos de servicios profesionales celebrados con esa institución, o entre las actividades y funciones del contrato que se pretende desempeñar y el puesto o puestos que desempeña en diversa institución.

Corresponde a la Dirección General de Organización y Remuneraciones de la Administración Pública Federal (DGOR) emitir el dictamen de compatibilidad, según se dispone en el punto 96 del artículo referido. Para emitir el dictamen requiere, como marca el punto 99, contar al menos con descripción y perfil del puesto que se pretende ocupar, así como del que ya se ocupa; dependencia donde se presta el servicio, ubicación del centro de trabajo, jornada de trabajo, particularidades, características y condiciones del puesto a ocuparse y del que ya se ocupa, como es uso de equipo técnico o exposición a riesgo; monto de honorarios. El punto 100 indica que el dictamen de compatibilidad debe hacer constar, entre otros aspectos si las funciones a desarrollarse son o no excluyentes entre sí, si implican o pudieran implicar conflicto de intereses; horario de trabajo de cada puesto; particularidades de cada puesto, ubicación de centros de trabajo; domicilio del trabajador.

Solamente en el caso de puestos de docencia, procede autorizar compatibilidad para el desempeño de más de un empleo, cargo, comisión o contrato en una misma institución, incluso misma unidad administrativa. Esta compatibilidad debe ajustarse a diversos límites máximos, como se dispone en el punto 97 del artículo indicado, que son hasta cuarenta y dos horas semanales, si dichas actividades son frente a grupo en diversa plaza, en uno o varios planteles o escuelas, o hasta cuarenta y ocho horas semanales, si tales actividades docentes están referidas a las categorías directiva o de supervisión.

En todas las hipótesis jurídicas mencionadas, en las que, contando el trabajador con el dictamen de compatibilidad necesario, en el caso de incapacidad temporal o definitiva, por riesgo de trabajo o enfermedad general, deberá el trabajador hacer extensiva esta incapacidad para efectos de las diversas relaciones burocráticas. 


\section{Acuerdo General del Pleno del Consejo de la Judicatura Federal, que establece las disposiciones en materia de actividad administrativa del propio consejo ${ }^{22}$}

El artículo 744 dispone que, para el ejercicio del gasto por concepto de viáticos y pasajes, las unidades ejecutoras de gasto deben sujetarse a: III. Es improcedente la autorización de comisiones cuando el personal desempeñe dos o más empleos compatibles, a menos que se obtenga licencia en el empleo o empleos distintos del que origine la comisión. No se autorizan comisiones, cuando el servidor público desempeña dos o más empleos compatibles, a menos que se obtenga licencia en el empleo o empleos distintos del que origine la comisión, de conformidad con el numeral 835 Nonies, fracción IV, del mismo Acuerdo.

\section{ENTIDADES FEDERATIVAS}

En las entidades federativas también se han expedido por los poderes legislativos correspondientes, ordenamientos jurídicos de derecho burocrático, cuyo fundamento son los artículos 115, fracción VIII, segundo párrafo, por lo que se refiere a los municipios, y 116, fracción VI, por lo que atañe a los estados, de la CPEUM, relacionados con la compatibilidad de funciones y empleos. En algunos casos sí procede, en otros no. Son de destacarse los siguientes:

\section{Baja California}

La Constitución Política del Estado Libre y Soberano de Baja California, ${ }^{23}$ dispone en el numeral 66, que los magistrados numerarios, jueces, consejeros de la judicatura, secretario general, secretarios auxiliares, de estudio y cuenta, del Poder Judicial del Estado, durante el tiempo de su encargo, aun cuando tengan carácter de interinos, no pueden aceptar ni desempeñar empleo o encargo en la Federación, estado o municipios ni de particulares, salvo los cargos no remunerados en asociaciones científicas, docentes, literarias o de beneficencia. Los magistrados supernumerarios, mientras no sean llamados

22 DOF, 2 de enero de 2015.

23 Periódico Oficial del Estado (POE), 16 de agosto de 1953. 
para cubrir una falta temporal o absoluta, pueden desempeñar empleo o encargo en la Federación, estado, municipios o particulares.

Los secretarios de acuerdos y actuarios del Poder Judicial del Estado, están sujetos a los mismos impedimentos a que alude el párrafo anterior, pero si podrán desempeñar cargos remunerados en asociaciones científicas, docentes, literarias o de beneficencia.

La Ley de Compatibilidad de Funciones, Empleos y Comisiones para el estado de Baja California ${ }^{24}$ establece en el numeral 1o. que el Ejecutivo puede autorizar la percepción a una misma persona, de las remuneraciones correspondientes a dos o más funciones, empleos o comisiones, con cargo al Presupuesto de Egresos del Estado, siempre que se dé cumplimiento a lo dispuesto por los artículos 7o. y 8o. de esta ley en aquellos casos en que se desempeñen empleos o comisiones federales y cumplan ciertos requisitos que la propia ley exige, entre los que es de destacarse al de que los horarios fijados para el desempeño de funciones, empleos o comisiones, sean compatibles entre sí sin que haya interferencia.

Las comisiones que se confieran a funcionarios o empleados dentro del mismo ramo en que presten sus servicios, son exclusivamente para integrar juntas y comisiones remuneradas con cargo a la partida correspondiente del presupuesto de egresos. En ningún caso una misma persona puede recibir más de tres remuneraciones de esta índole si presta sus servicios dentro del gobierno del estado, ni más de cuatro si no desempeña cargo alguno dentro del propio gobierno, de conformidad con el numeral 2o. del mismo ordenamiento.

El artículo 3o. dispone que las comisiones conferidas para la realización de una obra o estudio cierto y determinado, remunerados mediante el pago de honorarios, no deben exceder de dos en total por sí solas y en distintos ramos, o de una, si se perciben sueldos. Dentro de un mismo ramo, es incompatible la percepción de sueldos con la de honorarios, salvo que aquellos se perciban por el dictado de clases sobre la especialidad técnica o profesional por la cual se otorguen los honorarios. Únicamente se autoriza la percepción de honorarios y de nueve horas de dictado de clases semanarios, como máximo.

Es incompatible la percepción simultánea de becas y remuneraciones con cargo al presupuesto de egresos del estado. Igualmente es incompatible la percepción simultánea de pensiones y remuneraciones con cargo al erario estatal, según establece el numeral 5o.

El numeral 7o. indica que para percibir las remuneraciones correspondientes a dos o más cargos compatibles, de conformidad con esta ley, la persona

\footnotetext{
${ }^{24}$ POE, 20 de julio de 1967.
} 
interesada debe obtener una autorización expresa, previa solicitud firmada por el titular de la dependencia en la cual presta sus servicios, ante la Oficialía Mayor de Gobierno, la que debe otorgar dicha autorización conjuntamente con la Secretaría de Planeación y Finanzas, previo acuerdo expreso en cada caso del Ejecutivo del estado.

El trabajador que fuera incapacitado por riesgo de trabajo o por enfermedad general por el Instituto de Seguridad y Servicios Sociales de los Trabajadores del Gobierno y Municipios del Estado de Baja California (ISSSTECALI), debe hacer extensiva la misma para efectos de otros vínculos burocráticos.

\section{Ciudad de México}

La Constitución Política de la Cuidad de México ${ }^{25}$ dispone en el artículo 29, Del Congreso de la Ciudad, A. Integración, I. El Poder Legislativo se deposita en el Congreso de la Ciudad de México, 5. Las y los diputados, cuando estuvieren en ejercicio, no pueden desempeñar ninguna otra comisión o empleo públicos con goce de sueldo.

De igual forma, se establece en el artículo 38, Tribunal Electoral de la Ciudad de México: "2. Está integrado por cinco magistradas o magistrados electorales designados por el Senado de la República que actúan en forma colegiada y duran siete años en su encargo y no pueden desempeñar ningún otro empleo o comisión, con excepción de aquellos en actividades docentes, científicas, culturales o de beneficencia".

La Ley de Austeridad, Transparencia en Remuneraciones, Prestaciones y Ejercicio de Recursos de la Ciudad de México, ${ }^{26}$ establece en el artículo 102 que para la determinación de la remuneración de los servidores públicos se consideran las siguientes bases: "II. Ningún servidor público puede tener una remuneración igual o mayor que su superior jerárquico, salvo que: a) El excedente sea consecuencia del desempeño de varios empleos públicos, y b) La remuneración que sea producto de las condiciones generales de trabajo, derivado de un trabajo técnico calificado o por especialización en su función".

Dispone también en el numeral 115 que la Secretaría de Administración y Finanzas está facultada para dictar reglas de carácter general en las que se establezca: "I. Los casos en que proceda aceptar la compatibilidad para el desempeño de dos o más empleos o comisiones con cargo a los presupuestos

25 Gaceta Oficial de la Ciudad de México (GOCDMX), 5 de febrero de 2017.

26 GOCDMX, 31 de diciembre de 2018. 
de las Dependencias, Órganos Desconcentrados, Alcaldías y Entidades, sin perjuicio del estricto cumplimiento de las tareas, horarios y jornadas de trabajo que correspondan. Los interesados podrán optar por el empleo o comisión que les convenga cuando se dictamine que sus empleos no son compatibles".

La Ley del Notariado para la Ciudad de México, ${ }^{27}$ dispone que el ejercicio del oficio notarial es incompatible con toda dependencia a empleo, cargo o comisión público, privado o de elección popular, y con el ejercicio de la profesión de abogado en asuntos en que haya contienda. El notario tampoco puede ser comerciante, ministro de culto o agente económico de cualquier clase en términos de las leyes respectivas, de conformidad con el artículo 33.

\section{Guanajuato}

La Constitución Política del estado de Guanajuato, ${ }^{28}$ establece en el numeral 31 que los consejeros electorales locales y demás servidores públicos que establezca la ley no pueden tener otro empleo, cargo o comisión, con excepción de los no remunerados en actividades docentes, científicas, culturales, de investigación o de beneficencia.

El artículo 50 dispone que los diputados en ejercicio no pueden desempeñar ningún empleo, cargo o comisión públicos por el que se disfrute de sueldo, hecha excepción de los docentes, sin previa licencia del Congreso o de la Diputación Permanente; pero entonces cesarán en su función representativa mientras dure su nuevo cargo.

El artículo 91 preceptúa que los magistrados, los consejeros, los jueces, los secretarios y los actuarios del Poder Judicial no pueden ejercer la profesión de abogado, sino en negocio propio, de su cónyuge, de sus ascendientes o descendientes sin limitación de grado, ni desempeñar otro cargo o empleo público o privado, a excepción de los docentes.

El numeral 136, fracción III, dispone que ningún servidor público puede tener una remuneración igual o mayor que su superior jerárquico; salvo que el excedente sea consecuencia del desempeño de varios empleos públicos, en los términos del artículo 133, que su remuneración sea producto de las condiciones generales de trabajo, derivado de un trabajo técnico calificado o por especialización en su función.

27 GOCDMX, 11 de junio de 2018.

28 Publicada en el Periódico Oficial del estado (POE), 18 de octubre de 1917. 
La Ley para el Ejercicio y Control de los Recursos Públicos para el Estado y los Municipios de Guanajuato, ${ }^{29}$ regula en el artículo 86 que no pueden reunirse en un mismo individuo dos o más cargos o empleos públicos por los que perciba sueldo, sino con permiso especial del Congreso del Estado, exceptuándose los docentes.

La Ley del Trabajo de los Servidores Públicos al Servicio del Estado y de los Municipios para el estado de Guanajuato, ${ }^{30}$ dispone en el artículo 46 que son obligaciones de los titulares de las dependencias: "VI. Conceder licencias a sus trabajadores, sin menoscabo de sus derechos y en los términos de las condiciones generales de trabajo, en los siguientes casos: C) Para desempeñar cargos de elección popular". En el numeral 82 dispone que las condiciones generales de trabajo deben establecer: "IV. Las jornadas de trabajo; VI. El monto de los salarios".

El Primer Tribunal Colegiado en materia de Trabajo del Décimo Sexto Circuito dictó una tesis aislada en la que se resuelve que en los artículos 28 y 29 del Reglamento de las Condiciones Generales de Trabajo del Personal de la Secretaría de Educación de Guanajuato, se establece de cuántas horas están constituidas las jornadas y cuál es su duración; asimismo, se determina que la duración máxima de la jornada diurna no debe exceder de 8 horas diarias. En este sentido, si la trabajadora indica que se desempeñaba en dos plazas de base y que por cada una percibía prestaciones individuales y autónomas, no es dable considerar que laboró horas extras, si la jornada a la que se hace referencia corresponde a una plaza y, en el caso, la actora gozaba de dos plazas y en ninguna se excedía la jornada legal. En consecuencia, el reclamo de horas extras cuando no se advierte que las hubiera trabajado es improcedente pues, en todo caso, ese derecho le asistiría si excediera de la jornada legal por cada una de las plazas. ${ }^{31}$

\section{Jalisco}

La Constitución Política del estado de Jalisco ${ }^{32}$ dispone en el numeral 12 que el consejero presidente y los consejeros electorales deben percibir una re-

29 POE, 12 de agosto de 2003.

30 POE, 4 de diciembre de 1992.

31 Tesis: XVI.1o.T.53 L (10a.), Tribunales Colegiados de Circuito, Semanario Judicial de la Federación, Décima Época, 25 de enero de 2019.

32 Publicada en el Periódico Oficial del estado (POE), 21, 25 y 28 de julio y 1o. de agosto de 1917. 
muneración acorde con sus funciones que son establecidas en el Presupuesto de Egresos del Estado, conforme a los principios, bases y lineamientos que prevén la CPEUM, esta Constitución, las leyes y demás disposiciones reglamentarias que de ella emanen, la cual en ningún supuesto puede ser igual ni superior a la de los magistrados del Poder Judicial del Estado. No pueden tener otro empleo, cargo o comisión, con excepción de aquellos, no remunerados en que actúen en representación del Instituto o que desempeñen en actividades docentes, científicas, culturales, de investigación o beneficencia, no remunerados. El numeral 35 bis establece que: $\mathrm{m}$ ) Durante el ejercicio de su encargo, el Auditor Superior no puede militar o formar parte activa de partido político alguno, ni asumir otro empleo, cargo o comisión, salvo los desempeñados en asociaciones científicas, docentes, artísticas o de beneficencia y los no remunerados.

Todo cargo público de elección popular es incompatible con algún otro de la Federación, del Estado o del Municipio, cuando por ambos se perciba sueldo, salvo de los ramos de docencia, investigación científica y beneficencia. Los diputados, el gobernador y los magistrados, durante el periodo de su encargo, no podrán desempeñar ninguna otra comisión o empleo de la Federación, del estado o del municipio, por los cuales se disfrute sueldo o gratificación, sino con licencia previa del Congreso; pero, entonces, cesarán en sus funciones respectivas mientras dure la nueva ocupación. Se exceptúan los empleos y comisiones de docencia, culturales, científicos y de beneficencia, los cuales se podrán desempeñar sin incurrir en incompatibilidad. Lo anterior con fundamento en el artículo 112.

En el estado de Jalisco se expidió la Ley de Incompatibilidades para los Servidores Públicos, Reglamentaria del Artículo 112 de la Constitución Política del Estado de Jalisco. ${ }^{33}$

Esta ley dispone, en el numeral 3, que son nulos y carecen de eficacia legal, los acuerdos, nombramientos, designaciones y comisiones que la contravengan. Establece, en el artículo 4o., que hay incompatibilidad, cuando un servidor público desempeña distintos cargos públicos remunerados, conforme a lo dispuesto por los artículos 109 y 112 de la Constitución Política del Estado de Jalisco.

El artículo 5o. establece que ningún servidor público puede ocupar dos o más cargos directivos, ejecutivos ni administrativos remunerados, incompatibles, pero el artículo 6o. señala que no es incompatible el desempeño de cargos públicos con los de la actividad docente y de beneficencia, o de éstos entre sí. Las incompatibilidades de los cargos directivos, administrativos y do-

33 POE, 8 de enero de 1984. 
centes de la Universidad de Guadalajara se rigen por las normas de sus leyes Orgánica y Reglamentaria.

El Primer Tribunal Colegiado en materia Administrativa del Tercer Circuito resolvió en una tesis aislada que la Primera Sala de la Suprema Corte de Justicia de la Nación, en la jurisprudencia 1a. /J. 37/2017 (10a.), de título y subtítulo: "INTERPRETACIÓN CONFORME. NATURALEZA Y ALCANCES A LA LUZ DEL PRINCIPIO PRO PERSONA", estableció que la supremacía normativa de la Constitución Política de los Estados Unidos Mexicanos no sólo se manifiesta en su aptitud de servir como parámetro de validez de todas las demás normas jurídicas, sino también en la exigencia de que éstas, al aplicarse, se interpreten de acuerdo con los preceptos de aquélla, para que, de existir varias posibilidades de interpretación, se elija la que mejor se ajuste al mandato constitucional, porque esa supremacía intrínseca no sólo opera en el momento de creación de las normas, cuyo contenido ha de ser compatible con el texto constitucional, sino que se prolonga, ahora como parámetro interpretativo, a la fase de su aplicación y a su eficacia normativa directa, donde se añade su eficacia como marco de referencia o criterio dominante en la interpretación de las restantes. En consecuencia, la Ley de Incompatibilidades para los Servidores Públicos, Reglamentaria del Artículo 112 de la Constitución Política del Estado de Jalisco, que prevé el procedimiento a seguir respecto de los funcionarios que desempeñen dos puestos simultáneamente, debe interpretarse conforme al artículo de la Constitución local que reglamenta, en cuanto a que todo cargo público de elección popular es incompatible con algún otro de la Federación, del estado o del municipio, cuando por ambos se perciba sueldo, salvo los de los ramos de docencia, investigación científica y beneficencia; de ahí que dicha incompatibilidad sólo es aplicable a los servidores públicos señalados, es decir, a los que desempeñen más de un cargo, y uno de éstos sea de elección popular. De seguirse un procedimiento conforme a la ley indicada a sujetos distintos de los referidos, con independencia de la resolución que llegara a emitirse, por sí misma, ésta sería violatoria de derechos fundamentales. ${ }^{34}$

\section{Michoacán de Ocampo}

La Constitución Política del estado de Michoacán de Ocampo ${ }^{35}$ dispone en el artículo 28 que los diputados propietarios, durante el periodo de su encar-

34 Tesis: III.1o. A.1. CS (10a.), Tribunales Colegiados de Circuito. Semanario Judicial de la Federación, Décima Época, 11 de enero de 2019.

35 Periódico Oficial del Gobierno del Estado (POGE), 7, 10, 14, 17, 21, 24, 28 de febrero; 3, 7, 10 y 14 de marzo de 1918. 
go, no pueden desempeñar ninguna comisión o empleo de la Federación, del estado o del municipio por los cuales se disfrute sueldo, a excepción de los de instrucción pública y beneficencia, sin licencia previa del Congreso.

En el artículo 77 establece que los magistrados ejercen un periodo constitucional de cinco años y podrán ser reelectos hasta en dos ocasiones. Al término del periodo cesarán en sus funciones. El Congreso del Estado podrá privarlos de su encargo en cualquier tiempo, cuando incurran en falta de probidad u honradez, mala conducta, negligencia en el desempeño de sus labores o cuando acepten desempeñar otro empleo o cargo de la Federación, estados, municipios o particulares, salvo las actividades no remuneradas de la academia, docencia, investigación o de beneficencia y en los términos del Título Cuarto de esta Constitución y la Ley de Responsabilidades de los Servidores Públicos del Estado.

El numeral 153 dispone que los funcionarios de elección popular que sin causa justificada y sin la correspondiente licencia faltaren al desempeño de sus funciones, pierden la dotación remuneratoria que disfruten por ellas o por cualquier otro empleo que desempeñen; quedarán suspensos en sus derechos de ciudadanos y no podrán obtener ningún empleo que toque al servicio público. Estas privaciones las sufrirán por el tiempo que dure la omisión y no más.

El numeral 154 establece que todo cargo de elección popular es incompatible con el ejercicio de cualquier otro empleo del estado en que se disfrute sueldo, excepción hecha de los de instrucción y beneficencia, si no es que para desempeñarlo se obtenga licencia del Congreso.

La Ley de la Comisión Estatal de los Derechos Humanos del Estado de Michoacán de Ocampo ${ }^{36}$ dispone en el numeral 124 que las funciones del presidente, de los visitadores regionales y auxiliares, del secretario ejecutivo, del coordinador de orientación legal, quejas y seguimiento, del coordinador de estudios, divulgación y capacitación de los derechos humanos, de los subcoordinadores, del titular del órgano interno de control y la coordinación administrativa son incompatibles con el ejercicio de cualquier otro empleo, cargo o comisión en el sector público, partidos u organizaciones políticas, excepción hecha de los de instrucción y beneficencia siempre y cuando no interfieran con el horario de labores de la Comisión, tampoco podrán desempeñarse como ministro de culto religioso.

36 POGE, 21 de noviembre de 2014. 


\section{Nuevo León}

La Constitución Política del Estado Libre y Soberano de Nuevo León ${ }^{37}$ dispone en el artículo 141 que queda prohibido desempeñar a la vez dos o más cargos o empleos remunerados del Estado, de los municipios, o de uno y otros, o cualesquiera de ellos con uno de la Federación, sean o no de elección popular, con excepción de los relativos a la instrucción pública y beneficencia. Tampoco pueden desempeñar a la vez dos cargos de elección popular.

El Tercer Tribunal Colegiado en materia Administrativa del Cuarto Circuito, dictó una tesis aislada en la que interpretó que el artículo 141 de la Constitución Política del Estado Libre y Soberano de Nuevo León, al prohibir el desempeño a la vez de dos o más cargos o empleos remunerados del Estado, de los Municipios o de uno y otros, o cualquiera de ellos con uno de la Federación, sean o no de elección popular, no contraviene el artículo 127, segundo párrafo, fracción III, de la Constitución Política de los Estados Unidos Mexicanos, que señala que ningún servidor público podrá tener una remuneración igual o mayor que su superior jerárquico, salvo que, entre otras causas, el excedente sea consecuencia del desempeño de varios empleos públicos, toda vez que aquel precepto no tutela en sí el derecho a favor de cualquier servidor público de ejercer varios empleos remunerados de esa naturaleza, sino que casuísticamente prevé que si algún funcionario ejerce repetidamente la función pública, en los casos específicos en que las leyes así lo permitan, no podrá tener una remuneración en los términos correspondientes. En cambio, de una interpretación sistemática de los artículos 49, 62, 101, 116 y 125 de la carta magna, se llega a la convicción de que el respeto a nuestro sistema jurídico mexicano, en relación con la función pública, conlleva la indiscutible finalidad de que se prohíba a los servidores públicos la pluralidad de cargos remunerados, a efecto de honrar la labor que deben cumplir en el ejercicio de sus funciones, la cual se vería mermada porque no se cumplirían con los principios de división de trabajo, de carencia de ubicuidad y de honorabilidad. Además, la prohibición mencionada salvaguarda la legalidad, honradez, lealtad, imparcialidad y eficacia a las que están obligados todos los entes públicos en el ejercicio de sus funciones. ${ }^{38}$

El Tercer Tribunal Colegiado en materia de Trabajo del Cuarto Circuito resolvió en una tesis aislada que la cláusula 49 del Contrato Colectivo de Tra-

37 Periódico Oficial del estado (POE), 16 de diciembre de 1917.

38 Tesis: IV. 3o.A.20 A (10a.) Tribunales Colegiados de Circuito, Semanario Judicial de la Federación y su Gaceta, Décima Época, t. 2, libro XV, diciembre de 2012, p. 1541. 
bajo celebrado entre la Universidad Autónoma de Nuevo León y su sindicato, vigente en 2004, establece, en lo conducente, que no se expedirán nombramientos por más de una categoría; que en caso de que los trabajadores académicos desempeñen además funciones administrativas, la relación laboral con la universidad se entenderá como una sola para todos los efectos, y que lo mismo sucederá si los trabajadores docentes o administrativos laboran en dos o más de sus dependencias. Por otra parte, la diversa cláusula 153 del citado pacto dispone que los empleados que cumplan 30 años de servicios tienen derecho a la jubilación con el pago de una pensión consistente en el cien por ciento del sueldo y prestaciones. Ahora bien, del análisis de dichas cláusulas se concluye que son enunciativas y no limitativas, por lo que la falta de forma en un contrato tocante a una de las categorías no implica que ésta no se haya desempeñado, pues esa situación la subsana la Ley Federal del Trabajo en sus artículos 21 y 26 que prevén, respectivamente, que se presume la existencia de la relación laboral entre el que presta un trabajo personal y el que lo recibe; y que la falta por escrito del contrato es imputable al patrón, lo cual debe prevalecer frente a una posición contraria del pacto colectivo. Por tanto, si un trabajador de dicha institución percibía su salario por dos puestos, ambos deben tomarse en cuenta para efectos del cálculo de su jubilación, a pesar de que uno de ellos no sea considerado de base en el contrato colectivo de trabajo, y que no se haya otorgado una contratación formal al empleado conforme a él. ${ }^{39}$

\section{Oaxaca}

La Constitución Política del estado libre y soberano de Oaxaca ${ }^{40}$ dispone en el numeral 136, que nunca puede desempeñarse a la vez, por un solo individuo, dos o más empleos o cargos públicos del Estado y de los Municipios por los que se disfrute sueldo, honorarios, gratificación o cualquiera otra ministración de dinero, con excepción a los relativos a los ramos de educación y beneficencia públicas.

La Ley Orgánica del Poder Ejecutivo del Estado de Oaxaca ${ }^{41}$ establece en el artículo 19 que los titulares de dependencias y entidades a que se refiere

39 Tesis: IV. 3o. T.261 L. Tribunales Colegiados de Circuito, Semanario Judicial de la federación y su Gaceta, Novena Época, t. XXVIII, octubre de 2008, p. 2391.

40 Periódico Oficial del estado (POE), 4 de abril de 1922.

41 POE, 10 de noviembre de 2018. 
esta ley no pueden desempeñar ningún otro empleo, cargo o comisión públicos del estado y de los municipios, por los que disfruten sueldo, honorarios o gratificación o cualquier otra ministración de dinero, con excepción a los relativos a los ramos de educación y beneficencia pública.

La Ley Orgánica de la Universidad Autónoma "Benito Juárez" de Oaxaca, ${ }^{42}$ dispone en el numeral 68 que queda prohibida la acumulación de empleos y, en consecuencia, los funcionarios o empleados de la universidad sólo podrán desempeñar un cargo administrativo e impartir cátedra en facultad o escuela o realizar investigación en los institutos de la misma, de conformidad con lo dispuesto por los contratos colectivos de trabajo en vigor y el estatuto del personal correspondiente.

Ley de Responsabilidades de los Servidores Públicos del estado y Municipios de Oaxaca, ${ }^{43}$ dispone en el artículo 65, fracción XXI, que todo servidor público tiene las siguientes obligaciones: XXI.- Abstenerse de desempeñar algún otro empleo, cargo o comisión oficial o particular que la Ley prohíba, así como aquellos que no sean compatibles. La compatibilidad se da en dos o más empleos que se presten en distintas instituciones públicas y se desempeñen efectivamente las funciones en turnos diferentes o en horarios y jornadas de labores fijadas para la prestación del servicio, que no interfieran entre sí y se cumplan los requisitos y perfiles del o los puestos a desempeñar.

\section{San Luis Potosí}

La Constitución Política del Estado Libre y Soberano de San Luis Potosí14 dispone en el sexto párrafo del artículo 31 que los consejeros electorales y demás servidores públicos del Consejo Estatal Electoral y de Participación Ciudadana, no pueden tener otro empleo, cargo o comisión, con excepción de los no remunerados en actividades docentes, científicas, culturales, de investigación o de beneficencia. Tampoco pueden asumir un cargo público en los órganos emanados de las elecciones en cuya organización y desarrollo hubieren participado, ni ser postulados para un cargo de elección popular o asumir un encargo de dirigencia partidista, durante los dos años posteriores al término de su encargo.

\footnotetext{
42 POE, 7 de marzo de 1988.

43 POPE, 1 de junio de 1996.

44 Periódico Oficial del estado (POE), 2, 5, 9, 12, 16, 19, 23, 26 y 30 de enero; 2, 6 y 9 de febrero de 1918.
} 
El párrafo quinto del numeral 32 establece en el quinto párrafo que, durante el periodo de su encargo, los magistrados electorales no pueden tener ningún otro empleo, cargo o comisión, con excepción de aquellos en que actúen en representación de la autoridad electoral jurisdiccional local, y de los que desempeñe en asociaciones docentes, científicas, culturales, de investigación o de beneficencia, no remunerados.

El articulo 49 preceptúa que los diputados, desde el día en que rindan protesta de su encargo hasta aquél en que concluya el mismo, no pueden desempeñar, sin previa licencia del Congreso o de la Diputación Permanente, comisiones, cargos o empleos en los gobiernos, federal, estatal o municipal por los que devenguen sueldo; en cuyo caso cesarán en sus funciones representativas mientras dure la licencia. Los diputados suplentes, en ejercicio de sus funciones, están sujetos al mismo requisito. Se exceptúa de esta prohibición el empleo en el ramo de la educación pública.

El artículo 94 dispone que los funcionarios judiciales están impedidos para el libre ejercicio de la abogacía y no pueden desempeñar ningún otro cargo, empleo o comisión públicos o privados, salvo los de docencia y los de carácter honorífico, y percibirán una remuneración adecuada e irrenunciable.

El artículo 132 señala que ninguna persona puede desempeñar a la vez dos cargos de elección popular, pero la electa puede optar entre ambos el que quiera desempeñar. Jamás pueden reunirse en una misma persona dos empleos públicos por los que disfrute sueldo, exceptuando los del ramo de educación.

La Ley de los Trabajadores al Servicio de las Instituciones Públicas del Estado de San Luis Potosít5 establece en el numeral 52 que son obligaciones de los trabajadores al servicio de las instituciones públicas a que se refiere esta ley: XII.- No desempeñar otro empleo, cargo o comisión oficial o particular, que sean incompatibles con los horarios y ejecución de sus labores.

La Ley Orgánica de la Administración Pública del estado de San Luis Potosít6 establece en el numeral 15 que los servidores públicos del Poder Ejecutivo no pueden desempeñar ningún otro empleo, cargo o comisión en el Gobierno Federal, Estatal o Municipal por los que disfruten sueldo, con excepción de los del ramo de instrucción pública. Tampoco pueden desempeñar durante su encargo trabajos o empleos que las leyes les prohíban. Los titulares de las dependencias y entidades, así como los subsecretarios, directores, subdirectores y quienes ocupen puestos de rango semejante, deben atender de tiempo

45 POE, 8 de enero de 1996.

46 POE, 24 de octubre de 1997. 
completo las funciones de su encargo y no pueden desempeñar empleos o trabajos particulares que motiven conflictos de intereses en relación con sus atribuciones.

\section{Tamaulipas}

La Constitución Política del Estado de Tamaulipas ${ }^{47}$ dispone en el artículo 31 que los diputados propietarios, desde el día de su elección y los Suplentes en ejercicio, no pueden aceptar sin permiso del Congreso, empleo alguno de la Federación, del estado o de los municipios, por el cual se disfrute sueldo, excepto en el ramo de instrucción. Satisfecha esta condición y sólo en los casos en que sea necesario, el diputado queda suspenso en sus funciones de representante del pueblo por todo el tiempo que desempeñe la nueva comisión o empleo. Las mismas disposiciones rigen respecto a los diputados suplentes en ejercicio.

En el numeral 96 se establece que el secretario general de gobierno no puede desempeñar otro cargo, empleo ni comisión oficiales, remunerados, salvo en el ramo de educación.

El artículo 112 preceptúa que no pueden formar parte del Supremo Tribunal de Justicia, o del Consejo de la Judicatura, dos o más personas que tengan entre sí parentesco por consanguinidad hasta el cuarto grado, o por afinidad hasta el segundo. Ningún servidor público del Poder Judicial, aun con licencia, puede ser abogado de terceros, apoderado en negocios ajenos, asesor, árbitro de derecho o arbitrador, ni desempeñar ningún otro empleo, cargo o comisión, ya sea público o privado, por el que reciba remuneración alguna; salvo los casos de docencia, investigación, literatura o beneficencia. El numeral 128 dispone la organización del servicio de defensoría pública, tanto en materia penal como de representación en asuntos familiares o civiles y para el otorgamiento de asesorías legales. Tiene un titular designado por el Ejecutivo del estado y los defensores y asesores que sustente el presupuesto de egresos. Los defensores no pueden tener percepciones inferiores a las que corresponden a los agentes de Ministerio Público. El cargo de defensor público o de asesor es incompatible con cualquier otro cargo, empleo o comisión en los sectores público, social o privado, excepto en la realización de actividades docentes, de investigación, literarias o de beneficencia.

\footnotetext{
47 POE, 9 de febrero de 1921.
} 
La Ley de Educación del Estado de Tamaulipas ${ }^{48}$ dispone en el cuarto párrafo del artículo 76 Terreciese que las personas que decidan aceptar el desempeño de un empleo, cargo o comisión que impidan el ejercicio de su función docente, de dirección o supervisión, deben separarse del servicio, sin goce de sueldo, mientras dure el empleo, cargo o comisión.

La Segunda Sala de la Suprema Corte de Justicia de la Nación dictó jurisprudencia por contradicción de tesis, en la que sostiene que el artículo 27 de la Ley del Trabajo de los Servidores Públicos del Estado de Tamaulipas ${ }^{49}$ concede el derecho a la prima de antigüedad cuando el trabajador: "I. Haya laborado diez años o más; y, II. Se retire o sea separado de su trabajo". Ahora bien, tratándose de personal de la Secretaría de Educación del Estado de Tamaulipas, sus percepciones se integran parcialmente con las claves presupuestarias que determinan los lineamientos emitidos por la Federación, a través de la Secretaría de Educación Pública (SEP), con base en el Acuerdo Nacional para la Modernización de la Educación Básica que generó la carrera magisterial como un sistema de promoción horizontal, integrado por cinco niveles de estímulos económicos, que si bien representan un ingreso significativo para los docentes, no pueden considerarse parte del sueldo o salario básico previsto en el artículo 18 de la ley laboral estatal. A partir de lo anterior, cuando el trabajador prestó sus servicios en dos o más plazas controladas con diversas claves presupuestarias y, en consecuencia, percibió dos o más salarios y diversas prestaciones en cada una de ellas, si bien el referido artículo 27 no impone limitaciones en lo referente a las claves presupuestales y que la antigüedad es una sola, ello no significa que para estimar el salario base del cálculo para la prima de antigüedad deban sumarse los sueldos de las diferentes plazas, pues esas diversas percepciones, aun evitando considerar cualquier prestación ajena al sueldo, corresponden a los distintos empleos del trabajador, plazas que fueron asignadas en diversos tiempos y que, por tanto, generaron antigüedades independientes; de ahí que para determinar el salario básico de la cuantificación de la prima de antigüedad, debe estimarse aquel que corresponda a la plaza que genera el derecho a percibirla, es decir, en la que se hayan computado al menos diez años de servicios. ${ }^{50}$

\footnotetext{
48 POE, 23 de octubre de 1999.

49 POE, 6 de diciembre de 2001.

50 Tesis: 2a./J/109/2010, Segunda Sala, Semanario Judicial de la Federación y su Gaceta, Novena Época, t. XXXII, agosto de 2010, p. 441.
} 


\section{CONCLUSIÓN}

El derecho del trabajo, en la LFT, no regula expresamente la simultaneidad de empleos. Pero de las disposiciones de la misma, se desprende que ello es posible. La principal exigencia es que no exista traslape de horarios.

Subsiste la doble interpretación para el caso de que un trabajador presente sus servicios a un mismo patrón en dos puestos diferentes, en dos jornadas diferentes. También existe la posibilidad jurídica de que un trabajador preste simultáneamente servicios a dos, o más, patrones diferentes. Es conveniente que, en su caso, se informe a las instituciones aseguradoras de esta situación, cuidando que el trabajador siempre tenga el mismo número de seguridad social.

La regulación que, en el derecho burocrático, federal y local, se hace de la simultaneidad de empleos, es compleja, regulándose en diversos ordenamientos jurídicos.

La principal razón de ello es que los recursos públicos deben ser empleados de manera correcta, sin dar lugar a que aparezcan los trabajadores coloquialmente denominados aviadores, es decir, que aparecen en la nómina, cobran salario, pero que no se presentan a trabajar. También en virtud de que ocupar dos puestos diversos puede presentar conflicto de intereses para el servidor público. Se debe garantizar que el trabajador reúna los requerimientos necesarios para ocupar ambos empleos y que cumpla en ambos de forma eficiente y eficaz.

\section{BIBLIOGRAFÍA}

BOLAÑOS LINARES, Rigel, Derecho laboral burocrático. Lecciones para el patrón-Estado, los trabajadores de base y de confianza a su servicio y, sus prestadores de servicios personales y profesionales, México, Porrúa, 2010.

Martín Valverde, Antonio et al., Derecho del trabajo, Madrid, Tecnos, 2003. 